\title{
Socio-demographic and academic correlates of clinical reasoning in a dental school in South Africa
}

\author{
T. C. Postma and J. G. White \\ Dental Management Sciences, University of Pretoria, Pretoria, South Africa
}

Correspondence

Thomas Cornè Postma

Dental Management Sciences University of Pretoria

Bophelo Road

Gezina 0001

Pretoria 0001

South Africa

Tel: +27 123192553

Fax: +27 123192146

e-mail: corne.postma@up.ac.za

\begin{abstract}
Introduction: There are no empirical studies that describe factors that may influence the development of integrated clinical reasoning skills in dental education. Hence this study examines the association between outcomes of clinical reasoning in relation to differences in instructional design and student factors.

Materials and Methods: Progress test scores, including diagnostic and treatment planning scores, of fourth and fifth year dental students (2009-2011) at the University of Pretoria, South Africa served as the outcome measures in stepwise linear regression analyses. These scores were correlated with the instructional design (lecture-based teaching and learning $(\mathrm{LBTL}=0)$ or case-based teaching and learning $(\mathrm{CBTL}=1)$, students' grades in Oral Biology, indicators of socio-economic status (SES) and gender.
\end{abstract}

Results: CBTL showed an independent association with progress test scores. Oral Biology scores correlated with diagnostic component scores. Diagnostic component scores correlated with treatment planning scores in the fourth year of study but not in the fifth year of study. "SES" correlated with progress test scores in year five only, while gender showed no correlation. 
Conclusion: The empirical evidence gathered in this study provides support for scaffolded inductive teaching and learning methods to develop clinical reasoning skills. Knowledge in Oral Biology and reading skills may be important attributes to develop to ensure that students are able to reason accurately in a clinical setting.

Keywords: clinical reasoning; case studies; scaffolding; reading ability; South Africa; dental eductaion.

\section{Introduction}

Clinical reasoning skills are important competencies to develop in undergraduate dental curricula (1). The development of clinical reasoning skills in inexperienced students remains a daunting task, complicated by the multifaceted and ambiguous nature of clinical reasoning as a construct $(2,3)$.

The few existing empirical studies $(4,5)$ that describe the development of clinical reasoning skills in dental education over time are descriptive in nature, with little or no reference to student or teacher-related factors that may have influenced the learning process. It could be argued that the instructional design created by the teacher may have a distinct impact on how students approach their learning, while the characteristics and learning behaviours (6-9) of the students are probably equally important to consider.

A need therefore exists to examine the associations between clinical reasoning outcomes and different types of instructional designs used for teaching, as well as the students' characteristics that may influence their learning. An improved understanding of these connections may be valuable to the teacher to understand the dynamics of teaching and learning of clinical reasoning skills at undergraduate level.

\section{Teaching: Instructional designs}

Cognitive scientists propose that inductive approaches to teaching and learning are more likely than deductive approaches to develop complex reasoning (10). Case-based teaching and learning (CBTL) and clinical teaching and learning (CTL) can be considered to be inductive teaching and learning methods that facilitate active learning and problem-solving in relevant contexts $(10,11)$. Lecture-based teaching and learning (LBTL), in turn, can be defined as a deductive approach to teaching and learning, which is only suitable to teach conceptual knowledge (10). Inductive methods such as problem-based learning (PBL) have been employed by medical schools for several decades (12). Despite substantial research, there is still contention whether PBL is more effective than traditional LBTL to develop reasoning skills (13). Part of this contention has its origin in the way PBL evaluation data are being collected and compared using meta-analyses. Farrow and Norman argue that direct comparison of different instructional designs would be more appropriate than meta-analyses to gain a more sophisticated understanding of differences in impact on learning (13). 
The development clinical reasoning skills is however dependent on an instructional design that allows for the repeated elaboration of prior knowledge $(3,10,11)$. History dictates that the basic medical sciences (BMS) such as Anatomy and Physiology serve as prior knowledge for clinical teaching and learning (CTL) (14). BMS knowledge may indeed contribute to the development of clinical reasoning skills, particularly when integrated with clinical problems $(15,16)$. In a traditional dental school, Anatomy and Physiology typically form the basis of Oral Biology. Oral Biology serves as the scientific basis to understand the aetiology, pathogenesis, and diagnosis of diseases and conditions in the head and neck region (17). Ultimately, the quality of the diagnostic reasoning may influence treatment planning (18) and the outcome of clinical cases (19). A need consequently exits to control for levels of prior knowledge when evaluating teaching and learning outcomes (20).

\section{Learning: Student characteristics and behaviours.}

Student characteristics and learning behaviours (6-9) also play a role in the learning process. Unfortunately, students do not possess equal academic skills and self-regulation abilities to cope with tertiary studies (6-9). The development of these skills is often determined by the quality of primary and secondary schooling in a socio-political environment (21-23). The development of reading skills in particular have a distinct influence on the general knowledge of students that may be required for the acquisition of new knowledge and reasoning skills at a tertiary level $(20,24)$.

The above-mentioned arguments are particularly relevant in the South African context in which Black Africans, Coloureds ${ }^{1}$ and Asians have been discriminated against in the Apartheid political system before 1994. This led to inequality in the education system that affected quality schooling for the majority of people in the country negatively for very long periods of time (21-23). Redress has slowly but surely been taking place since 1994. The South African government still uses "race" as a variable in census surveys to monitor redress in the country (25). Recent census data suggests that despite considerable redress, White South Africans are still better resourced on average compared to the other groups (25). Hence, White students may still have the educational advantage in the South African context due to their socio-economic advantage. A recent article in Medical Education highlights the critical importance of including "race" as a socio-demographic indicator into educational study designs to measure redress (26).

The above-mentioned socio-demographic traits of students are bound to have a distinct influence on how students learn. However, it is ultimately the individual student's selfregulation ability that will determine the learning outcomes (6). Motivation to learn and conscientious engagement in the educational process have indeed been linked to academic success (27). Literature, for example, suggests that females generally outperform male students, probably because of their inherent diligence $(8,9)$. The inclusion of gender as a covariable in an outcomes evaluation may therefore be warranted.

\footnotetext{
${ }^{1}$ People with mixed race origins

${ }^{2}$ Third, fourth and fifth year students wrote exactly the same test during the study period (2009-2011)
} 


\section{Objectives and hypotheses of the study}

Following the appraisal above, the primary objective of this research was to study the multivariate association between clinical reasoning outcomes, prior BMS knowledge, the instructional design students were exposed to and student-related socio-demographic factors.

It was expected that inductive methods such as CBTL would be associated with superior clinical reasoning ability while LBTL would be associated with lesser ability in clinical reasoning in an academic context. The researchers also expected a correlation between students' Oral Biology grades (as indicator of BMS knowledge) and diagnostic reasoning, as well as a correlation between the diagnostic reasoning and treatment decisions.

A further hypothesis was that students in a tertiary education setting, who have more resources at their disposal, might still have an advantage above students with fewer resources at their disposal. It was also anticipated that females will engage in the learning more thoroughly and will as a result display superior clinical reasoning compared to males.

\section{Materials and Methods}

This study was conducted in the discipline-based School of Dentistry, University of Pretoria from 2009 to 2011.

\section{Institutional context: Instructional Design}

For the past few decades integrated clinical reasoning has been facilitated by means of a subject named Comprehensive Patient Care (CPC) (5, 11, 28-31). Until 2009 CPC comprised of lecture-based teaching and learning (LBTL) in combination with clinical teaching and learning (CTL) in the fourth year of study, which continued until the end of the fifth year of study $(5,11,31)$. Case-based teaching and learning (CBTL) were implemented in 2009 for third year students. The purpose of the CBTL were to systematically scaffold the development of clinical reasoning skills $(11,31)$. During teaching learning and assessment students had to study complex case studies and had to record the clinical information on patient administration forms, after which they had to determine the aetiology and formulate diagnoses $(5,31)$. The diagnoses then served as the basis for the treatment planning. The students performed these tasks individually and in groups (31). It is pertinent to note that the faculty members responsible for CPC remained the same over the study period. These faculty members participated, in some way or another, in both the LBTL and CBTL.

Clinical teaching and learning (CTL) commenced in the fourth year $(5,11,31)$ applying the principles learned during CBTL. Students examined, diagnosed and treated a minimum of eight complex cases under the guidance of the same faculty members that present the CBTL. In the fifth year of study the responsibility of the supervision of the diagnosis and treatment planning was transferred to the Department of Prosthodontics when the students started to practise fixed prosthodontics (31). It is important to note that this transfer was part of an 
intentional scaffolding strategy whereby the scaffolding was gradually removed as the students increased their proficiency $(11,31)$.

\section{Institutional context: BMS knowledge}

At the time of the study dental students at the University of Pretoria learned Anatomy and Physiology in the first and second years of study. During the study period students received Oral Biology lectures in the third year of study and had to study from world class text book (17) using study objectives as their only guide. For many years Oral Biology has been the module with the highest failure rate in the third year of study. The same lecturer presented Oral Biology for each of the calendar years applicable to this study. The assessment in Oral Biology was done by means of random sampling of study objectives. The assessment consisted of three written papers throughout the year as well as a final examination. Although the students received feedback, the content and old papers were strictly not available to students for use as part of their learning. Questions differed from test to test.

\section{Target population}

Fourth and fifth year students (2009-2011) served as the study population (Table 1). The 2009 and 2010 fourth year cohorts received LBTL, while the 2011 fourth year cohort had CBTL in 2010 in the third year of study. The 2009 and 2010 fifth year cohorts had LBTL in their fourth year of study while the 2011 fifth year cohort participated in the CBTL in their third year of study (2009).

Table 1 Outline of the target population

\begin{tabular}{|l|c|c|c|c|c|c|c|c|}
\hline Study year & 4 & 4 & 4 & & 5 & 5 & 5 \\
\hline Year & & 2009 & 2010 & 2011 & 2009 & 2010 & 2011 \\
\hline $\mathbf{n}$ & & 49 & 39 & 48 & 48 & 48 & 36 \\
\hline Instructional design & & LBTL & CBTL & CBTL & LBTL & LBTL & CBTL \\
\hline
\end{tabular}

\section{Outcome measure: Progress test scores}

The researchers measured the clinical reasoning ability of third to fifth year students with a standardised progress test ${ }^{2}$ at the end of the second semester (2009-2011). The test was based on a complex case-study. The students had to gather the necessary information and had to make 18 diagnostic and 14 treatment planning decisions. The diagnostic decision-making included the identification of aetiological factors $(5,31)$. The test and its discrimination properties (which were deemed to be acceptable) have been published in the European Journal of Dental Education (5) and can also be viewed in the original $\mathrm{PhD}$ thesis (31).

Indicators of prior knowledge

Oral Biology grades were obtained from University records.

\footnotetext{
${ }^{2}$ Third, fourth and fifth year students wrote exactly the same test during the study period (2009-2011)
} 


\section{Socio-demographic indicators}

Students provided written consent the researchers to use their demographic details ("race" and "gender") on the University systems.

Using census data (25) and the students" "race" as reference the students were stratified into two categories indicating "socio-economic status" (SES) (33). White students were placed in the "high" SES group while Black African, Coloured and Asian students were grouped together in a category of "low" SES. This stratification was made because of the sociopolitical reasons $(26,33)$ provided in the introduction of this article and because the subsample sizes of some of the minority groups have been too small to be used independently in multivariate analyses (34).

\section{Statistical analysis}

The association between progress test scores (including diagnostic and treatment planning component scores) and the applicable instructional design (LBTL $=0$ or $C B T L=1$ ), Oral Biology grades, race, and gender, was analysed with stepwise linear regression in Stata (StataCorp. 2011. Stata Statistical Software: Release 12. College Station, TX: StataCorp LP). Stepwise linear regression was selected to identify independent co-variables that could be associated with clinical reasoning outcomes by systematically eliminating co-variables that were unlikely to have a correlation. The normal distribution of the data (31) also in indicated the use linear regression. Progress test scores served as the outcome measure.

Effect sizes were measured by means of Cohen's $f^{2}$. According to the Cohen method effect sizes of $0.02,0.15$ and 0.35 are, respectively, considered to be low, medium and large (35).

\section{Ethical approval}

The researchers obtained ethical approval from the Ethics Committee of the Faculty of Health Sciences, University of Pretoria (Protocol 153/2009) to conduct the analysis as part of a broader PhD study.

\section{Results}

Table 2 displays the mean progress test scores per cohort broken down to diagnostic and treatment planning scores in relation to students' exposure to CBTL or LBTL. Table 2 also displays the mean Oral Biology grades for each cohort. 
Table 2 Progress test (5) and Oral Biology scores

\begin{tabular}{|c|c|c|c|c|c|c|c|c|c|c|c|}
\hline \multirow[t]{2}{*}{ Year } & \multirow[t]{2}{*}{$\begin{array}{l}\text { Study } \\
\text { year }\end{array}$} & \multirow[t]{2}{*}{$n$} & \multirow[t]{2}{*}{$\begin{array}{l}\text { Instruc- } \\
\text { tional } \\
\text { design }\end{array}$} & \multicolumn{2}{|c|}{$\begin{array}{l}\text { Progress test } \\
\text { scores } \\
\text { (\%) }\end{array}$} & \multicolumn{2}{|c|}{$\begin{array}{l}\text { Diagnostic } \\
\text { component } \\
\text { (\%) }\end{array}$} & \multicolumn{2}{|c|}{$\begin{array}{l}\text { Treatment planning } \\
\text { component } \\
\text { (\%) }\end{array}$} & \multicolumn{2}{|c|}{$\begin{array}{l}\text { Oral Biology } \\
\text { (\%) }\end{array}$} \\
\hline & & & & $x$ & Sd & $x$ & Sd & $x$ & Sd & $x$ & Sd \\
\hline 2009 & 4 & 49 & LBTL & 58.74 & 9.33 & 67.35 & 12.45 & 47.67 & 9.82 & 61.72 & 14.9 \\
\hline 2010 & 4 & 39 & CBTL & 66.59 & 10.69 & 73.79 & 12.99 & 57.33 & 12.53 & 62.72 & 8.30 \\
\hline 2011 & 4 & 48 & CBTL & 68.95 & 10.40 & 73.38 & 12.71 & 63.24 & 13.66 & 62.13 & 10.5 \\
\hline 2009 & 5 & 48 & LBTL & 64.97 & 9.71 & 71.75 & 11.34 & 56.25 & 13.87 & 61.25 & 10.6 \\
\hline 2010 & 5 & 48 & LBTL & 63.67 & 11.14 & 68.87 & 14.66 & 56.99 & 14.4 & 61.38 & 14.80 \\
\hline 2011 & 5 & 36 & CBTL & 75.69 & 6.93 & 83.64 & 7.96 & 65.48 & 11.13 & 63.47 & 8.06 \\
\hline
\end{tabular}

X: Mean

Sd: standard deviation

Table 3 provides the students' mean progress test scores stratified by population-based SES and gender.

Table 3 Progress test scores stratified by SES and gender

\begin{tabular}{|c|c|c|c|c|c|c|c|c|c|c|c|c|}
\hline \multirow[t]{2}{*}{ SES } & \multirow[t]{2}{*}{ YOS } & \multirow[t]{2}{*}{ ID } & \multirow[t]{2}{*}{ Year } & \multicolumn{3}{|c|}{ Female } & \multicolumn{3}{|c|}{ Male } & \multicolumn{3}{|c|}{ Total } \\
\hline & & & & $n^{*}$ & $x$ & $S D$ & $\mathrm{n}^{*}$ & $x$ & SD & $\mathrm{n}^{*}$ & $x$ & $\mathrm{SD}$ \\
\hline \multirow{6}{*}{ "Low" } & 4 & LBTL & 2009 & 6 & 59.38 & 11.86 & 7 & 56.70 & 10.59 & 13 & 57.94 & 10.80 \\
\hline & 4 & CBTL & 2010 & 6 & 66.67 & 13.79 & 3 & 56.25 & 14.32 & 9 & 63.20 & 14.04 \\
\hline & 4 & CBTL & 2011 & 14 & 66.96 & 8.10 & 6 & 63.02 & 12.41 & 20 & 65.78 & 9.43 \\
\hline & 5 & LBTL & 2009 & 7 & 63.84 & 11.81 & 6 & 49.48 & 14.31 & 13 & 57.21 & 14.51 \\
\hline & 5 & LBTL & 2010 & 4 & 77.34 & 10.94 & 2 & 79.69 & 2.21 & 6 & 78.12 & 8.62 \\
\hline & 5 & CBTL & 2011 & 8 & 57.03 & 7.61 & 5 & 61.25 & 7.19 & 13 & 58.65 & 7.46 \\
\hline \multirow{6}{*}{ "High" } & 4 & LBTL & 2009 & 23 & 56.66 & 8.75 & 12 & 63.54 & 8.03 & 35 & 59.02 & 9.02 \\
\hline & 4 & CBTL & 2010 & 21 & 66.96 & 10.11 & 9 & 69.10 & 8.33 & 30 & 67.60 & 9.52 \\
\hline & 4 & CBTL & 2011 & 18 & 74.65 & 10.66 & 8 & 65.63 & 7.83 & 26 & 71.87 & 10.61 \\
\hline & 5 & LBTL & 2009 & 22 & 65.77 & 9.32 & 12 & 66.67 & 8.14 & 34 & 66.09 & 8.81 \\
\hline & 5 & LBTL & 2010 & 21 & 74.55 & 6.03 & 9 & 76.74 & 7.98 & 30 & 75.21 & 6.61 \\
\hline & 5 & CBTL & 2011 & 25 & 67.00 & 10.48 & 10 & 68.13 & 6.72 & 35 & 67.32 & 9.48 \\
\hline
\end{tabular}


Table 4 Multivariate correlation of progress test in relation to instructional design, Oral Biology grades, SES, and gender

\begin{tabular}{|c|c|c|c|c|c|c|c|}
\hline & $\begin{array}{l}\text { Out- } \\
\text { come }\end{array}$ & Covariable & Coefficient & SE & $\mathbf{P}$ & Adjusted R² & $\begin{array}{l}\text { Cohen's } \\
f^{2} \\
\end{array}$ \\
\hline \multirow{16}{*}{ 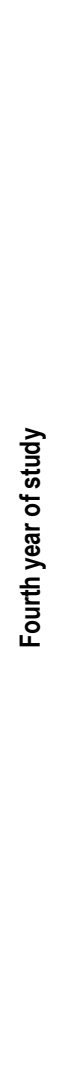 } & \multirow{5}{*}{ 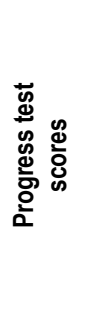 } & Intervention $(\mathrm{Yes}=1 / \mathrm{No}=0)$ & $8.62(5.23-12.01)$ & 1.71 & $<0.001$ & & \\
\hline & & Oral Biology & $0.35(0.21-0.48)$ & 0.07 & $<0.001$ & & \\
\hline & & SES (High=1 / Low=0) & & & $\mathrm{ns}^{*}$ & & \\
\hline & & Gender $($ Male $=1 /$ Female $=0)$ & & & $\mathrm{ns}^{*}$ & & \\
\hline & & & & & & 0.27 & 0.37 \\
\hline & \multirow{5}{*}{ 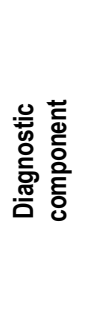 } & Intervention $(\mathrm{Yes}=1 / \mathrm{No}=0)$ & $5.27(1.09-9.45)$ & 2.11 & $<0.05$ & & \\
\hline & & Oral Biology & $0.44(0.27-0.61)$ & 0.09 & $<0.001$ & & \\
\hline & & SES (High=1 / Low=0) & & & $\mathrm{ns}^{*}$ & & \\
\hline & & Gender $($ Male $=1 /$ Female $=0)$ & & & $\mathrm{ns}^{*}$ & & \\
\hline & & & & & & 0.19 & 0.23 \\
\hline & \multirow{6}{*}{ 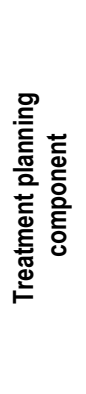 } & Intervention $(Y e s=1 / \mathrm{No}=0)$ & $11.54(7.17-15.90)$ & 2.21 & $<0.001$ & & \\
\hline & & Oral Biology & $0.11(-0.08-0.30)$ & 0.10 & 0.26 & & \\
\hline & & Diagnostic component score & $0.26(0.09-0.44)$ & 0.09 & $<0.01$ & & \\
\hline & & SES (High=1 / Low=0) & & & $\mathrm{ns}^{*}$ & & \\
\hline & & Gender $($ Male $=1 /$ Female $=0)$ & & & $\mathrm{ns}^{*}$ & & \\
\hline & & & & & & 0.27 & 0.37 \\
\hline \multirow{16}{*}{ 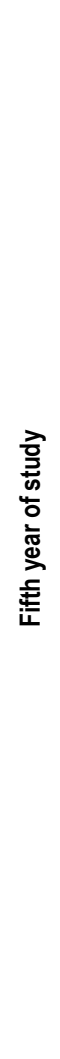 } & \multirow{5}{*}{ 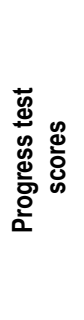 } & Intervention $(\mathrm{Yes}=1 / \mathrm{No}=0)$ & $10.21(6.69-13.74)$ & 5.73 & $<0.001$ & & \\
\hline & & Oral Biology & $0.20(0.06-0.34)$ & 2.76 & $<0.001$ & & \\
\hline & & SES (High=1 / Low=0) & $4.68(0.77-8.59)$ & 2.37 & $<0.05$ & & \\
\hline & & Gender $($ Male $=1 /$ Female $=0)$ & & & $\mathrm{ns}^{*}$ & & \\
\hline & & & & & & 0.31 & 0.45 \\
\hline & \multirow{5}{*}{ 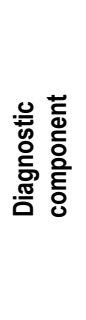 } & Intervention $(Y e s=1 / \mathrm{No}=0)$ & $12.12(7.67-16.56)$ & 2.25 & $<0.001$ & & \\
\hline & & Oral Biology & $0.27(0.08-0.45)$ & 2.88 & $<0.01$ & & \\
\hline & & SES (High=1 / Low=0) & $4.08(-0.84-9.01)$ & 1.64 & 0.103 & & \\
\hline & & Gender (Male=1 / Female $=0$ ) & & & $\mathrm{ns}^{*}$ & & \\
\hline & & & & & & 0.27 & 0.37 \\
\hline & \multirow{6}{*}{ 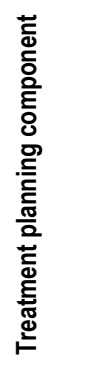 } & Intervention $(Y e s=1 / \mathrm{No}=0)$ & $6.30(0.63-11.97)$ & 2.87 & $<0.05$ & & \\
\hline & & Oral Biology & $0.12(-0.10-0.34)$ & 0.11 & 0.274 & & \\
\hline & & Diagnostic component score & $0.13(-0.08-0.33)$ & 0.10 & 0.219 & & \\
\hline & & SES (High=1 / Low=0) & $4.99(-0.73-10.71)$ & 2.89 & 0.087 & & \\
\hline & & Gender $($ Male $=1 /$ Female $=0)$ & $4.32(0.62-9.27)$ & 2.50 & 0.086 & & \\
\hline & & & & & & 0.12 & 0.14 \\
\hline
\end{tabular}


Table 4 displays the results of the multivariate analysis for the fourth and fifth year cohorts using progress test scores, diagnostic, and treatment planning scores as the outcome variables

\section{Fourth year of study}

CBTL and Oral Biology grades exhibited positive associations with the progress test scores (adjusted $\mathrm{R}^{2}=0.27, f^{2}=0.37$ ) and diagnostic component scores (adjusted $\mathrm{R}^{2}=0.19, f^{2}=0.23$ ) in the fourth year of study. CBTL and the diagnostic component scores correlated independently with the treatment planning component scores (adjusted $\mathrm{R}^{2}=0.27, f^{2}=0.37$ ) (Table 4).

Fifth year of study

CBTL, Oral Biology grades and "high" SES, correlated with the progress test scores (adjusted $\mathrm{R}^{2}=0.31, f^{2}=0.45$ ) in the fifth year of study. CBTL and Oral Biology grades correlated with the diagnostic component scores (adjusted $\mathrm{R}^{2}=0.27, f^{2}=0.37$ ). Only CBTL could be independently associated with the treatment planning component scores (adjusted $\left.\mathrm{R}^{2}=0.12, f^{2}=0.14\right)($ Table 4).

\section{Discussion}

This article is the first known report of the multivariate association between clinical reasoning decision-making, different teaching and learning approaches, prior BMS knowledge in the form of Oral Biology grades, and socio-demographic variables in dental education.

\section{Progress test scores versus the teaching and learning approach}

The results of this study suggest that the preclinical scaffolded CBTL (11) may have been more effective compared to the previously used LBTL to develop undergraduate dental students diagnostic and treatment planning decision-making in CPC. Based on the Cohen method (35), the effect sizes of these differences ranged from medium to large. These results therefore support the use of inductive approaches to develop integrated reasoning skills over time, as opposed to deductive approaches (10) as elaborated upon in the introduction of this article. Moreover, the comparison of outcomes in relation to two different instructional designs (13) provides additional support to existing conclusions in medical education that inductive instructional designs such as PBL may be more effective than traditional LBTL methods to develop reasoning skills in the long-term (12).

\section{Progress test scores versus BMS knowledge}

The independent correlation, with medium to large effect sizes (35), that were found in the current study between progress test scores and Oral Biology grades (Table 4) suggests that BMS knowledge may indeed provide a foundation for the development of diagnostic reasoning skills in particular. The deliberate attempt to integrate knowledge obtained from Oral Biology in CPC during CBTL may have contributed to the positive correlations between 
Oral Biology grades and progress test scores. The current study's findings are therefore consistent with other reports in the literature in medical education (15).

An alternative explanation for the above-mentioned correlation may be variances in the students' ability to read and comprehend complex text (16, 20, 24, 36-38). A lack of reading skills is of particular concern in the South African schooling system $(36,37)$, which was explained in the introduction of this article. The University of Pretoria expects students to study Oral Biology from a world class text book (17), which requires good reading skills in order to comprehend the scientific language. The complex case studies $(5,31)$ used for teaching and learning as well for the progress test contain large amounts of information, which has to be interpreted and systematically transferred to odontograms (11) in a limited time period. Comprehension of the text is required to answer the 32 questions accurately. It has been proposed in the literature that students who have better reading skills will find similar exercises easier than students with less-developed reading skills $(16,38)$. Reading ability remains an important skill for any professional scholar and should therefore be promoted as a foundational skill from early on in the curriculum (37). Students who struggle with reading and comprehension should be identified early in order to be exposed to additional exercise to develop these critical skills (37).

Regardless of the potential confounding influence of reading ability, it can confidently be argued that diagnostic reasoning has a direct link with BMS knowledge as has been illustrated in previous research (15).

\section{Diagnostic reasoning versus treatment planning decisions}

Treatment planning, in turn, depends more on the diagnosis (39) and less on the BMS knowledge itself. Students at the University of Pretoria are taught to make a complete diagnosis before formulating a treatment plan based on their diagnostic findings and prognostic considerations (31). During the study period the same group of faculty members supervised and controlled this process during CBTL and CTL in the third and fourth years of study, respectively. The researchers therefore expected some sort of correlation between the diagnostic component and treatment planning component scores. The independent correlation, with a relatively large effect size (35) found between diagnostic component and treatment planning component scores in the fourth year of study (Table 4), indeed suggests that students who were able to make better diagnostic decisions were also able to make more accurate treatment planning decisions.

The relatively low scores achieved by fifth year students in the treatment planning component of the progress test may be indicative of the long time it normally takes to develop treatment planning skills (19). The results also indicate substantial misconception regarding treatment plan selection amongst the students, highlighting the need for further intervention. This need was elaborated upon in a related study by Postma and White (5). Moreover, the finding of the non-significant correlation between the diagnostic component and treatment planning component scores in the fifth year of study (Table 4) maybe a case of "case" or "content" specificity (40). It is highly conceivable that common misconception about treatment plan selection may have arisen due to lack of standardisation in the discipline-based school $(5,31)$. 
The risk for content specificity increased because of the transfer of primary supervision responsibility to a different academic department, indicating the need for greater levels of standardisation in the discipline-based school. This issue, however, needs further investigation. The finding that CBTL correlated with the treatment planning component scores in the fifth year analysis, without an association with the diagnostic component score, suggest that the treatment planning learned in the CBTL may well have contributed towards the treatment planning decisions in the progress test. However, the relatively low variance that could be explained $\left(\mathrm{R}^{2}=0.12\right)$ and low effect size (Cohen's $f^{2}=0.14$ ) (Table 4) indicate that other factors, that were not controlled for during the analysis, may have played a significant role in a student's acquisition of treatment planning skills. Literature indeed suggests that due the complexities of treatment planning, high variability may exist amongst inexperienced clinicians $(5,19)$. Further study is indicated into these dynamics.

\section{Progress test scores, SES and gender}

The detailed breakdown of the progress test scores (Table 3), suggests that those in the "high" SES grouping have an advantage to develop their skills in an academic setting. These findings may partly be due to inequality in reading ability that was identified in the introduction and discussion sections above $(36,37)$. However, controlling for potential confounding factors by means of the multivariate analysis, an association between SES and progress test scores could only be shown in the fifth year of study in relation to overall progress test scores. This finding might be related to the removal of the scaffold and support to the students by dedicated faculty, focussed on the teaching of clinical reasoning skills. As mentioned above, fifth year students were transferred to a different department for the supervision and control of diagnosis and treatment planning as part of a deliberate scaffolding strategy $(10,11,31)$. As a remedy to the situation, a qualitative study by Postma recommends additional support to students who do not progress in clinical reasoning (41). It should therefore be investigated whether the faculty responsible for CPC should continue to scaffold and support the learning of students performing at a lower level in the fifth year of study.

Studies have shown that females may perform marginally better than males in an academic setting due to their inherent diligence $(8,9)$. Gender could not be associated with progress test scores in the current study (Table 4). This may be due to the active learning approaches that were followed in the class room. Although a substantial amount of work had to be done at home, all students had to engage in team work in class. Scheduled periods had specific outcomes and, faculty members were on hand to provide supervision and feedback. It therefore appears as if active learning activities, as described above, may have levelled the playing field between males and females in an academic setting.

\section{Limitations of the study}

The above-mentioned inferences should only be interpreted considering the quasiexperimental design whereby the clinical reasoning outcomes of different student cohorts were compared (42). Such experimental designs are not ideal because the learning environment may change over time. Cohorts may be inherently different (42), as for example indicated by differences in the standard deviations of Oral Biology scores (Table 2) in the 
current study. These variances can be explained by the fact that the 2009 fourth year cohort had a few more struggling students in Oral Biology in the third year of study compared to the other cohorts. Due to ethical considerations the quasi-experimental design was the best available design that allowed for a comparison between students exposed to different instructional designs. Moreover, Oral Biology tests differed over the years that may have introduced measurement error. It could, however, be argued that the standard and level of difficulty, indicated by the similarity of the mean scores in Oral Biology (Table 2) remained consistent across cohorts for the duration of the study.

The stratification of SES may also have led to some degree of measurement error. Using this method it was assumed that the SES of the students in each stratum was the same, which is obviously not accurate on an individual level. The related results should therefore only be interpreted on a socio-demographic population-level (33).

The way in which the clinical reasoning outcomes were determined by means of the 32question progress test can also only be regarded as a simulation exercise, which may differ from a real clinical context.

Despite these limitations, the researchers are of the opinion that the methods that were employed over a three-year study period and adequate sample sizes allowed for inferences to be drawn with some confidence.

\section{Conclusion}

The empirical evidence gathered in this study provides support for the hypotheses that inductive teaching and learning methods such as CBTL would render superior clinical reasoning ability compared to LBTL. The findings support the use of scaffolded preclinical CBTL.

The results also support the hypothesis that knowledge in Oral Biology may be important to ensure that students are able to reason accurately in a clinical setting, although reading ability may be a confounding factor in this association. It is suggested that relevant BMS knowledge be integrated with CBTL and that the development of reading ability be pursued early in the curriculum in the South African context.

The hypothesis that SES may play a role in the acquisition of clinical reasoning skills could not be confirmed with confidence. A need may exist to scaffold and support the learning of students who are performing at a lower level throughout the duration of their undergraduate studies in the South African context. 


\section{References}

1 Plasschaert AJ, Holbrook WP, Delap E, Martinez C, Walmsley AD. Profile and competences for the European dentist. Eur J Dent Educ 2005: 9: 98-107.

2 Khatami S, Macentee MI. Evolution of clinical reasoning in dental education. J Dent Educ 2011: 75: 321-328.

3 Norman G. Research in clinical reasoning: past history and current trends. Med Educ 2005: 39: 418-427.

4 Crespo KE, Torres JE, Recio ME. Reasoning process characteristics in the diagnostic skills of beginner, competent, and expert dentists. J Dent Educ 2004: 68: 1235-1244.

5 Postma TC, White JG. Developing integrated clinical reasoning competencies in dental students using scaffolded case-based learning - empirical evidence. Eur J Dent Educ 2015: doi: 10.1111/eje.12159

6 Zimmerman BJ. Investigating self-regulation and motivation: historical background, methodological developments, and future prospects. Am Educ Res J 2008: 45: 166-183.

7 Ommundsen Y, Haugen R, Lund T. Academic self-concept, implicit theories of ability, and self-regulation strategies. Scand J Educ Res 2005: 49: 461-474.

8 Jedrychowski J, Lindemann R. Comparing standardized measures of diligence and achievement with dental student academic performance. J Dent Educ 2005: 69: 434-439.

9 Ferguson E, James D, Madeley L. Factors associated with success in medical school: systematic review of the literature. Br Med J 2002: 324(7343): 952-957.

10 Van Merriënboer JJ, Clark RE, De Croock MB. Blueprints for complex learning: the 4C/ID-model. Education Tech Research and Dev 2002: 50: 39-64.

11 Postma TC, White JG. Developing clinical reasoning in the classroom - analysis of the 4C/ID-model. Eur J Dent Educ 2015: 19: 74-80. doi: 10.1111/eje.12105

12 Strobel J, van Barneveld A. When is PBL more effective? A meta-synthesis of metaanalyses comparing PBL to conventional classrooms. IJPBL 2009: 3: 44-58.

13 Farrow R, Norman G. The effectiveness of PBL: the debate continues. Is meta-analysis helpful? Med Educ 2003: 37: 1131-1113.

14 Flexner A. Medical Education in the USA and Canada: A report to the Carnegie Foundation for the Advancement of Teaching. Boston, MA: Updyke, 1910.

15 Woods NN, Brooks LR, Norman GR. The value of basic science in clinical diagnosis: creating coherence among signs and symptoms. Med Educ 2005: 39: 107-112.

16 Eva KW. What every teacher needs to know about clinical reasoning. Med Educ 2004: 39: 98-106.

17 Nanci A. Ten Cate's oral histology: development, structure, and function. St Louis, Missouri: Mosby Elsevier, 2008.

18 Charlin B, Tardif J, Boshuizen HP. Scripts and medical diagnostic knowledge: theory and applications for clinical reasoning instruction and research. Acad Med 2000: 75:182-190.

19 Anders Ericsson, K. Deliberate Practice and Acquisition of Expert Performance: A 
General Overview. Acad Emerg Med 2008: 15: 988-994. doi: 10.1111/j.15532712.2008.00227.x

20 Shapiro AM. How including prior knowledge as a subject variable may change outcomes of learning research. Am Educ Res J 2004: 41: 159-189.

21 Van der Berg S. Apartheid's enduring legacy: Inequalities in Education 1. J Afr Econom 2007: 16: 849-880.

22 Burch VC. Medical education in South Africa: assessment practices in a developing country. [doctoral thesis]. Rotterdam: Erasmus University Rotterdam; 2007.

23 Burch VC, Sikakana CN, Yeld N, Seggie JL, Schmidt HG. Performance of academically at-risk medical students in a problem-based learning programme: a preliminary report. Adv Health Sci Educ Theory Pract 2007: 12: 345-358.

24 Levy BA, Hinchley J. Individual and developmental differences in the acquisition of reading skills. In: Carr TH, Levy BA, eds. Reading and its development: Component Skills Approaches. San Diego: Academic Press Inc, 1990: 81-128.

25 Statistics South Africa. Statistical Release Census 2011. Pretoria: Statistics South Africa, P0301.4.

26 Muzzin L, Mickleborough T. What does 'race' have to do with medical education research? Med Educ 2013: 47: 760-767.

27 Rijdt C, Stes A, Vleuten C, Dochy F. Influencing variables and moderators of transfer of learning to the workplace within the area of staff development in higher education: research review. Educ Res Rev 2013: 8: 48-74.

28 Seeliger JE, Snyman WD. A new approach to undergraduate dental education. JDASA 1996: 51: 746-749. Epub 1996/12/01.

29 Snyman WD, Ligthelm AJ. The new Pretoria curriculum. SADJ 2000: 55: 642-648.

30 Snyman WD, Kroon J. Vertical and horizontal integration of knowledge and skills - a working model. Eur J Dent Educ 2005: 9: 26-31.

31 Postma TC. Evaluating the impact of adjunctive integrated case-based dental teaching and learning on clinical reasoning in a discipline-based teaching and learning environment. [doctoral thesis]. Pretoria: University of Pretoria; 2014: 1-346.

32 Case SM, Swanson DB. Constructing written test questions for basic and clinical sciences 3 ed (revised). Philadelphia: National Board of Medical Examiners, 2002: 1180.

33 Särndal CE, Swensson B, Wretman J. Model assisted survey sampling. New York: Springer Science \& Business Media, 2003: 366-367.

34 Postma TC. Screening tools to prioritize routine dental care in an institutional environment. Mil Med 2007: 172: 1287-1292.

35 Cohen J. Statistical Power Analysis for the Behavioral Sciences (2nd Edition). Hillsdale, NJ: Lawrence Earlbaum Associates, 1988.

36 Fleisch B. Primary education in crisis: Why South African schoolchildren underachieve in reading and mathematics. Cape Town: Juta and Company Ltd, 2008: 1-162.

37 Bharuthram S. Making a case for the teaching of reading across the curriculum in higher education. S Afr J Educ 2012: 32: 205-214. 
38 Veenman MV, Beishuizen JJ. Intellectual and metacognitive skills of novices while studying texts under conditions of text difficulty and time constraint. Learn Instr 2004: 14: 621-640.

39 Kassirer JP. Teaching clinical reasoning: case-based and coached. Acad Med 2010: 85: $1118-1124$.

40 Dory V, Gagnon R, Charlin B. Is case-specificity content-specificity? An analysis of data from extended-matching questions. Adv Health Sci Educ 2010: 15: 55-63.

41 Postma TC. Self-regulation - the key to progress in clinical reasoning? Afr J Health Professions Educ 2015;7(2) DOI:10.7196/AJHPE.411: [In print].

42 Eccles M, Grimshaw J, Campbell M, Ramsay C. Research designs for studies evaluating the effectiveness of change and improvement strategies. Qual Saf Health Care 2003: 12: 47-52. 
